\title{
PURAWALOKANAYA - The Virtual Tour to Ancient City of Polonnaruwa - Sri Lanka
}

\author{
M. D. Thiwanka \\ Sri Lanka Institute of \\ Information Technology \\ Sri Lanka
}

\author{
W. S. V. Senanayake \\ Sri Lanka Institute of \\ Information Technology \\ Sri Lanka
}

\author{
R. H. A. C. N.Ranasinghe \\ Sri Lanka Institute of \\ Information Technology \\ Sri Lanka
}

\author{
P. K. C. Supeshala \\ Sri Lanka Institute of Information Technology \\ Sri Lanka
}

\author{
Y. D. Jayaweera \\ Sri Lanka Institute of Information Technology \\ Sri Lanka
}

\begin{abstract}
Virtual Reality (VR) or Virtual Environments (VE) has become a hot topic in modern research. Virtual reality is defined as the description of a three dimensional computer generated environment where a human can interact and explore. This research paper explains the design and the development of a virtual reality application named "Porawalokanaya", modeled "Polonnaruwa", an ancient city in Sri Lanka. It is important to look for ways where technology can be used to preserve prestigious heritage of a county. Porawalokanaya aimed to build realistic 3D models capturing the miniature detail of ancient Sri Lankan architecture and merged into an Android based virtual reality application. The users of the application will be able to experience visiting the city as they do in the real world. The application comprise of narration and a mini-map. Along with the 3D models of the important ancient buildings, the application has modeled the natural environment to give more realistic feeling to the user. The models were created using Autodesk Maya 2016 and Autodesk Mudbox 2016. The application was built in Unity Platform with C\# scripts.
\end{abstract}

\section{General Terms}

Modeling, Realistic, Sri Lanka

\section{Keywords}

3D Model, VR (Virtual Reality), Modeling, 360 view, Realistic, Ancient City, Polonnaruwa, Virtual Reality Environment.

\section{INTRODUCTION}

The history Polonnaruwa goes as far as 6th century BC, and it is the second main kingdom of Sri Lanka. Due to the invasion of Cholas Polonnaruwa has been destroyed and abandoned. When the time is changing this remaining ruins will go into pieces. The future generations will not be able to view the majestic kingdoms from the proud history. VR applications are the newest technology that is used to model real world applications in a $3 \mathrm{D}$ environment so users would be able to get same experience as they get in the real world. There are few VR applications are built based on ancient cities but none for the city of Polonnaruwa. This Application can be used for entertainment plus education purposes since this gives details about History of Polonnaruwa as well as the architectural concepts of that era. "Purawalokanaya" will provide accurate information with $3 \mathrm{D}$ objects where user can get a clear view on the Polonnaruwa city and the buildings. The main aim was to preserve Sri Lanka's heritage which has become ruins and to protect the ancestors' magnificent work for the future. The application comprise of the Palace of the king Parakramabahu and the surrounding in a 3D realistic environment. This research paper highlights similar work, methodology followed, results and future work.

\section{LITERATURE REVIEW}

This section presents the major work in literature that has been published which are mostly related to Virtual Reality, $3 \mathrm{D}$ reconstruction of archeological sites and town-scraping.

Enrico [1] presented the background and motivation of virtual environment research. Virtual reality should strive to make users interact with virtual worlds in the same way interact with real worlds, to achieve these goals inventors had to deeply observe how user inputs and output are handle based on the basic human interactions. Some application areas were benefits are more straightforward than others such as virtual prototyping, simulators and training, Telepresence and teleportation and augmented realty. To make an environment that always same as the environment that user lives the software part is not enough hardware part also needed, by using methods such as position/orientation tracking, eye tracking or full body motion users interact with the virtual environment.

Dylla described virtual reconstruction of entire city of ancient Rome. "City Engine" Software was used to design the entire city. In developing process designers focused on two methods, 1. Procedural Modeling (Create large scale 3D environments within defined rules and parameter ranged) 2. Parametric Modeling (well described rules which generate ancient temple models) these two methods made the process very efficient without dropping detail or quality of the 3D objects [2]. Cho and Daniel explains a concept in mapping texture from multiple camera views onto 3D-object models for Computer Animation. Rotating the camera in virtual environment, the texture view from different angles gives different views. The rendering of this $3 \mathrm{D}$ model represented by a wireframe does not give the realistic view of the $3 \mathrm{~d}$ object. Importing a texture give the view [3]. Craighead et.al in 2007 have shown how textures are created from the input file, texturing views (topdown views, texturing from two different sides) and the cause for the image color discrepancies to appear on the rendered surface [4]. Lights and Optics- range of techniques and 
mathematical models which attempt to simulate the complex behavior of light as it bounces and interacts with the world [5].

Following table gives a comparison of Purawalokanaya and other existing systems.

Table 1 : Comparison with other Systems

\begin{tabular}{|c|c|c|c|c|c|}
\hline 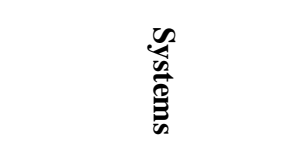 & 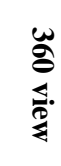 & 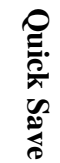 & 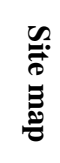 & 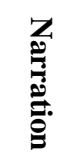 & 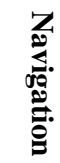 \\
\hline Rome Reborn [6] & Yes & No & No & Yes & No \\
\hline $\begin{array}{l}\text { Ancient City of Karnak } \\
\text { [7] }\end{array}$ & Yes & No & No & Yes & No \\
\hline $\begin{array}{l}\text { Explore the Acropolis } \\
\text { of Athens in Virtual } \\
\text { Reality [8] }\end{array}$ & Yes & No & No & Yes & No \\
\hline $\begin{array}{l}\text { Ancient city of } \\
\text { Pompeii [9] }\end{array}$ & Yes & No & No & Yes & No \\
\hline $\begin{array}{l}\text { Virtual 3D of Angkor } \\
\text { Wat temple [10] }\end{array}$ & Yes & No & No & Yes & No \\
\hline Purawalokanaya & Yes & Yes & Yes & Yes & Yes \\
\hline
\end{tabular}

During the literature survey it was found that Virtual Reality (VR) applications are becoming important and been used in many fields such as educational, engineering, science, entertainment, medical, archaeology and etc. Already lot of VR applications have been created. The focus here was on exploiting the capabilities of virtual worlds to enhance the visiting experience in a city of Polonnaruwa. Very few VR applications which created base on archaeology, those VR applications have many issues. For example issues like graphical issues, image based process, less realistic animations, map issues etc. "Purawalokanaya" is the best solution for archaeologists, students and people who are interested in history, mainly about Sri Lankan history. There are many different features added to "Purawalokanaya" application which are distinct from other VR applications.

\section{METHODOLOGY}

The development of "Purwalokanaya" followed the prototype methodology. Because it helps to identify critical functions and missing functionalities. When selecting methodology developers concerned about the development cost and time, Clarity of the initial requirements, Reliability, Application complexity, Time scheduling and Schedule visibility.

\subsection{Planning}

This is the first phase in the Application development process. It identifies whether or not there is the need for a new system to achieve team's strategic objectives. The purpose of this phase is to find out the scope of the problem and determine solutions, resources, costs, time and benefits. As the first step the research team conducted a feasibility study on locations to be selected as the most suitable place to apply the research solution. After all the required information is gathered, the team divided task among team members, with each member having an equal amount of work such as Information Gathering, Interface Designing, 3D modeling, Coding etc.

During phase, the team studied a number of documents, research papers, and existing solutions. The team also studied existing technologies relevant to the project to use in implementing the system.

\subsection{Analysis}

The team considered the functional requirements of the Application. It was also where system analysis takes place-or analyzing the needs of the end users to ensure the new application can meet their expectations. After selecting the suitable place as the Polonnaruwa Kingdom the research team carried out a thorough analysis of this place by collecting data from various sources.

The gathering of data was done in two aspects which are:

$$
\begin{aligned}
& -\quad \text { Primary data } \\
& -\quad \text { Secondary data. }
\end{aligned}
$$

The primary data was gained by the interviews the team had with Archaeologist. The team gathered secondary data by analyzing books, tour guides, articles, similar applications, research papers, videos and questionnaire. According to the received responses from questionnaire, it clearly showed that most of people are interested about the VR experience and the Sri Lankan history.

\subsection{Design and Development}

This phase describes how we expected to develop our Application. During the design phase, the research team prepared what should be the basic functionalities of the application and the interfaces were been sketched according to the gathered requirements All the included models, texturing and vegetation parts were created by using Autodesk Maya 2016, Autodesk Mudbox 2016, ZBrush. Before modeling the objects team had to discover the needed natural environment objects which are look like more realistic. When modeling the objects and the environment, main target was to create realistic 3D environment which helpful to feel the realistic procedure environment to the user.

First model which was designed is Kiri Wehera. This large stupa known as the Kiri Vehera of Polonnaruwa, lying north of Lankathilaka Pilima Ge is said to be built by a queen of king Parakramabahu called "Subadra". The original name of this has been "Rupavathi Stupa" and this too is a part of Ãlahana Privena and stands 80 feet in height today. This stupa is also the second biggest stupa in Polonnaruwa today. Also it is the only stupa to survive the 900 years of forces of nature and still is in the original condition. There are many restored smaller stupas around Kiri Vehera. These have been identified as burial chambers of high priests and royals. Many of these including Kiri Vehera stupa has been attacked by treasure hunters and their valuables looted.The two identical stupas south to the Lankathilaka is thought to be built upon remains of a king and a queen [11]. This model was created by using Autodesk Maya Software with a Maya Textures and Materials.

Model is described in Fig 1 and Fig 2. 


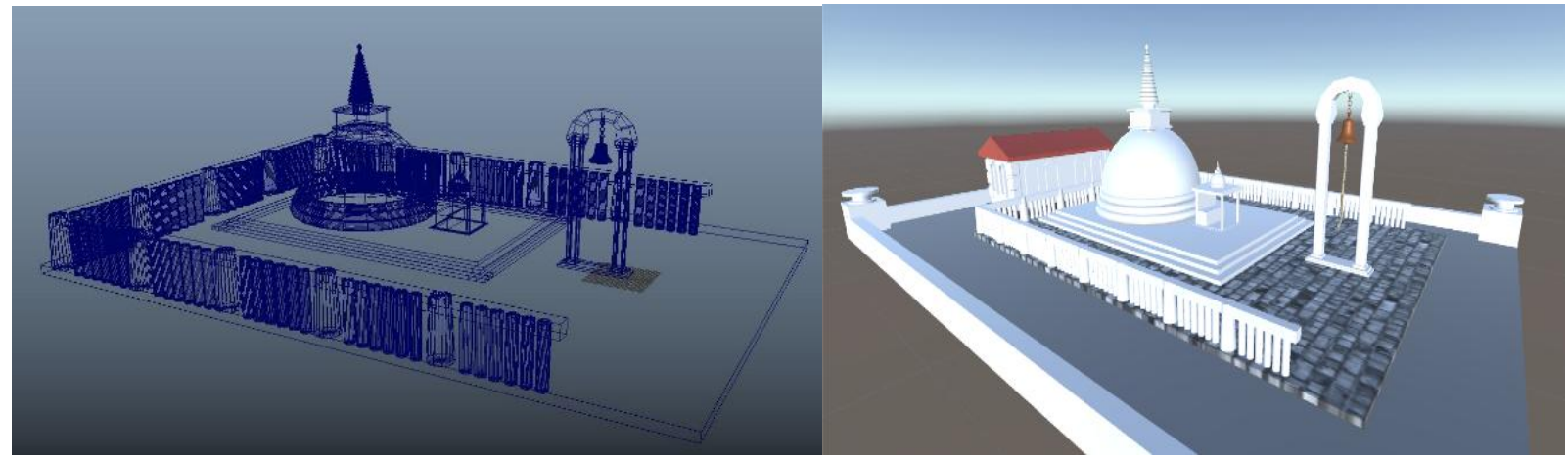

Fig. 1: Model of the Kiri Vehera without texturing

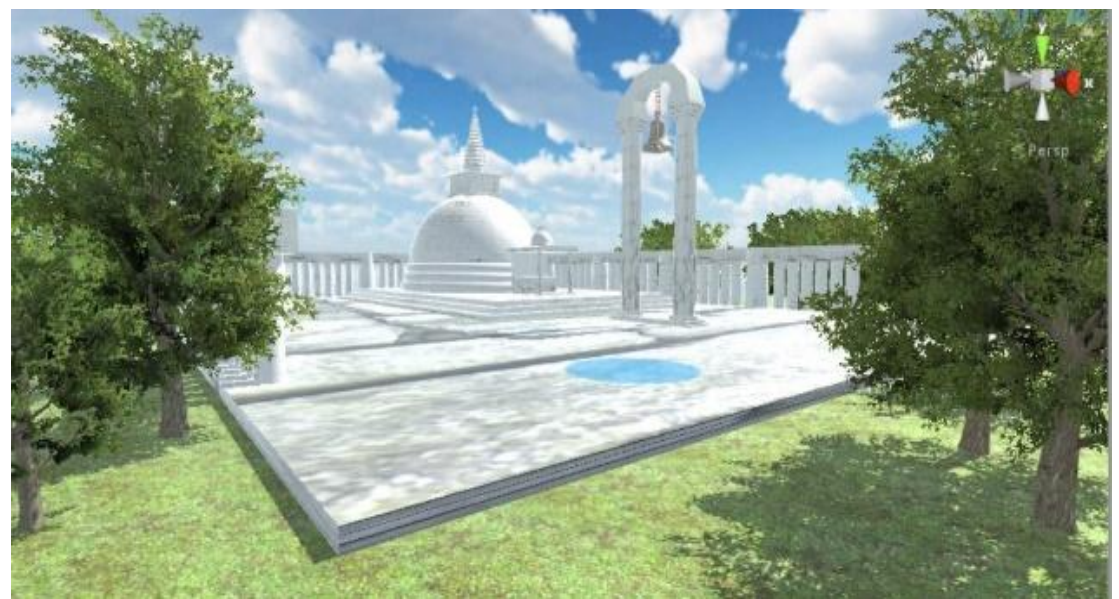

Fig. 2: Final Model of the Kiri Vehera

The second model was the Royal Palace. his is the Royal Palace of Polonnaruwa. The Royal Palace of King Parakumba was constructed as seven story building, but now remains only parts of 3 floors. This also known as Veijeyanthi Prasada According to the Mahawansa, the construction of this place took around seven years and seven months. Historical records says that this has 1000 rooms, but today you can see only ruins of 55. The building is made up with thick brick walls.
Still you can see the remaining two arrays of holes, done on the wall to hold the structure of the wooden floor. The Parakamabahu Palace was destroyed by south Indianan invader call "Maga", and burned. Still you can see some parts of burned bricks and walls inside [11]. This model was created by using Autodesk Maya Software with a Maya Textures and Materials. Model is described in Fig 3 and 4.

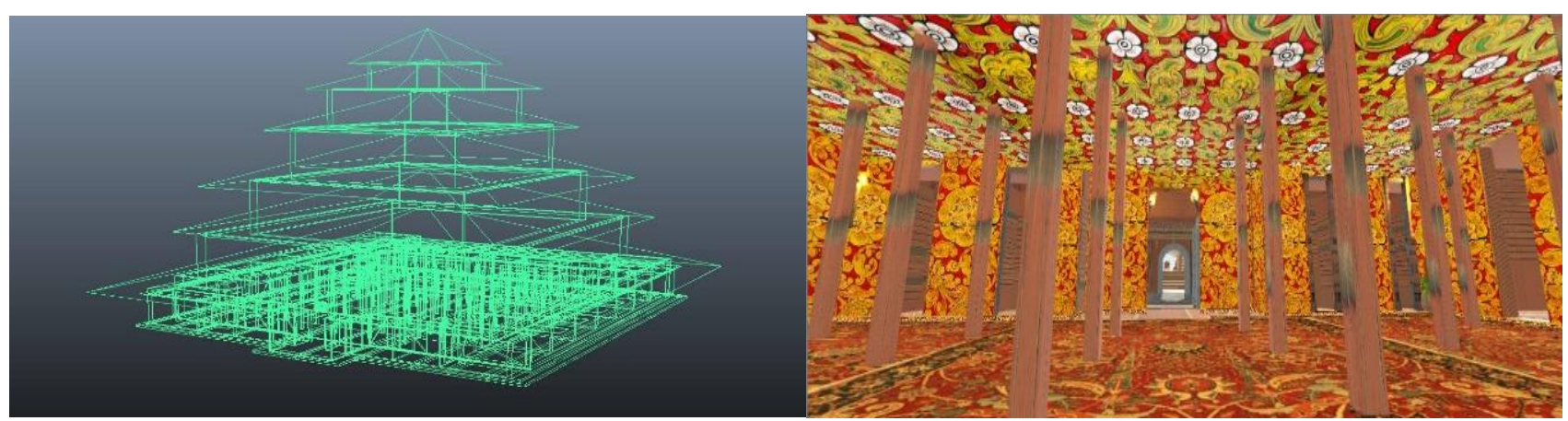

Fig. 3. Model of the Royal Palace without texturing 


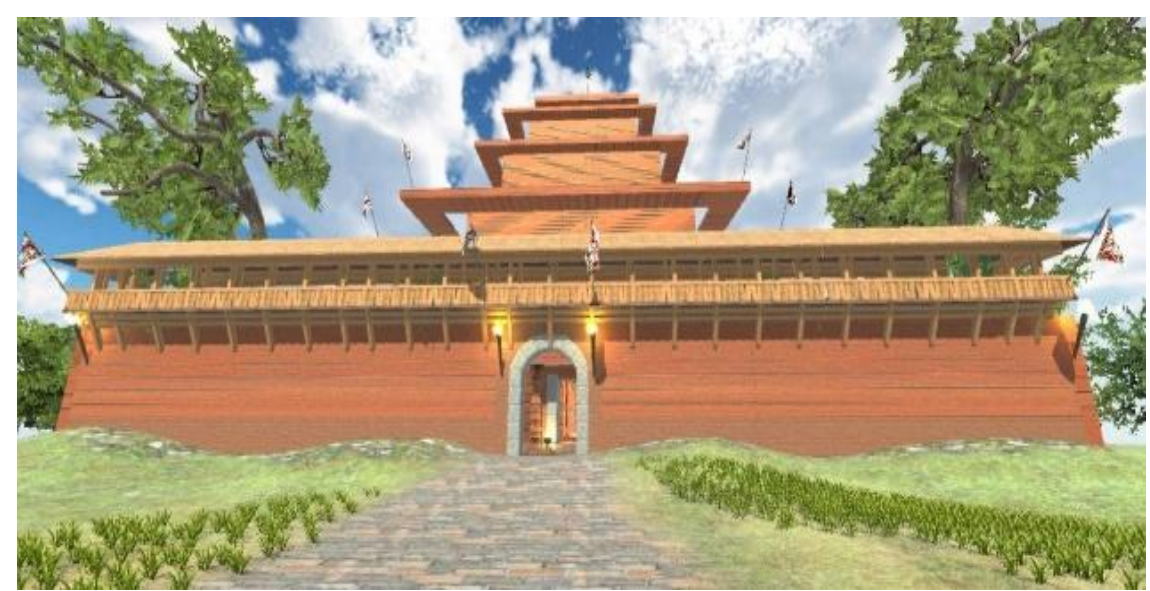

Fig. 4. Final Model of Royal Palace

Third model is the council chamber. This is the Council Chamber (Raja Sabahawa) of king Parakaramabahu the Great. This also known as Raja Vaishyabhujanga Mandapaya. The Council chamber is 75 feet in length and 33 feet width. The design was done in three tires. The first, lowest level was decorated with row of elephants and the second level with lions. Third and the upper most wall is decorated with
Vamana rupa. There are 4 rows with 12 stone pillars in each raw. Each pillar is decorated with carvings. It is believed that the roof supported on the stone pillars probably done with wood and clay tiles. This structure was undergone some renovation during the Dabadeniya period [11]. This model was created by using Autodesk Maya Software with a Maya Textures and Materials. Model is described in Fig 5 and 6.

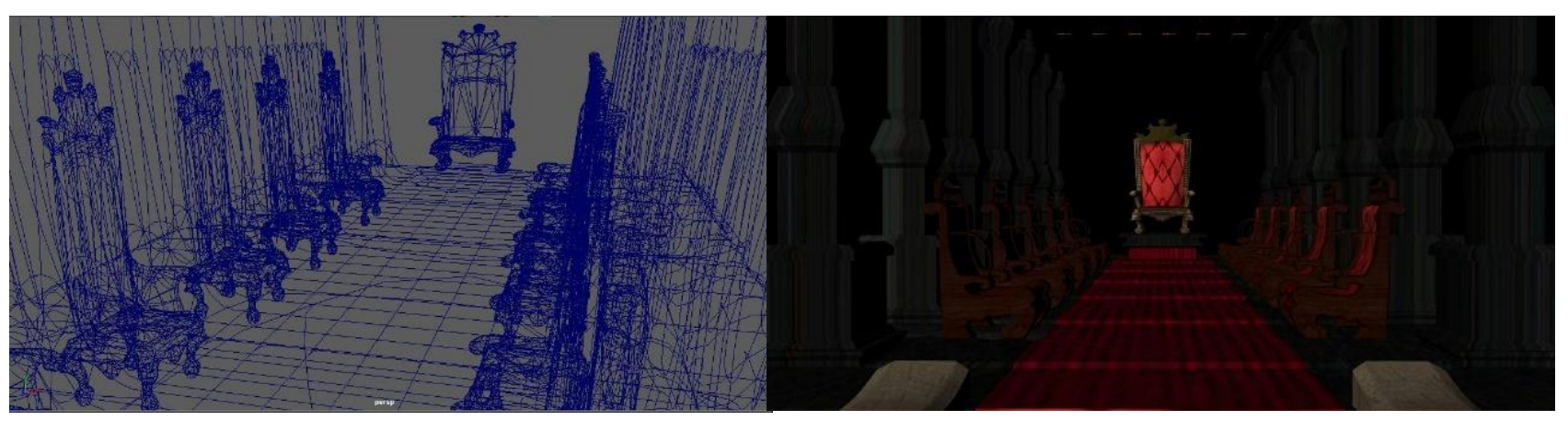

Fig. 5. Model of the Council Chamber without texturing

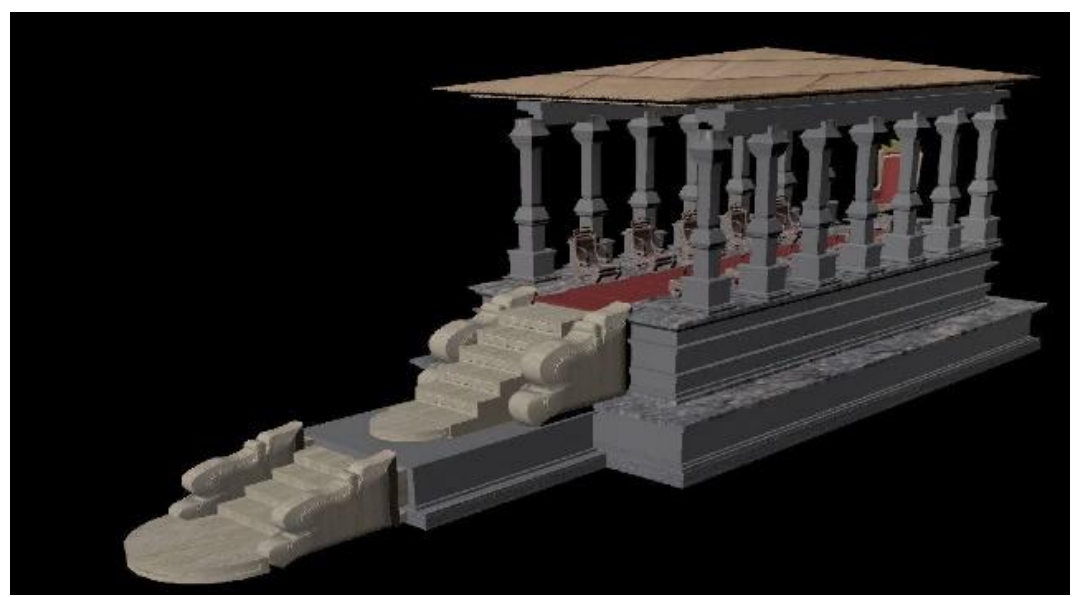

Fig. 6. Final Model of the Council Chamber

The final model was Kumara Pokuna. Kumara Pokuna (Prince Pond) is located close to the palace complex of the Pollonarauwa ancient city. During those days, Royal baths were must include item in ancient palace complex design. This pond is located in lower level than the complex and it that makes the easy flow of water to the pond. Kumara Pokuna was built during the king Parakumbahu time (11531186 AD). According to the archeologists, this must be the pond named as "Sila Pokkharani", referred in Mahawansa. And they believe that this pond belongs to "Nandana Uyana", great king Prarakaramabahu's Royal Park.Kumara pond is square in shape. The nearby canal was the watercourse for this pond and an outlet is allows to drain out the used water. Water flows in to the pond via two Makarara sprouts which are located besides the entrance. The pavilion located by the pond was used as the changing room [11].This model was created 


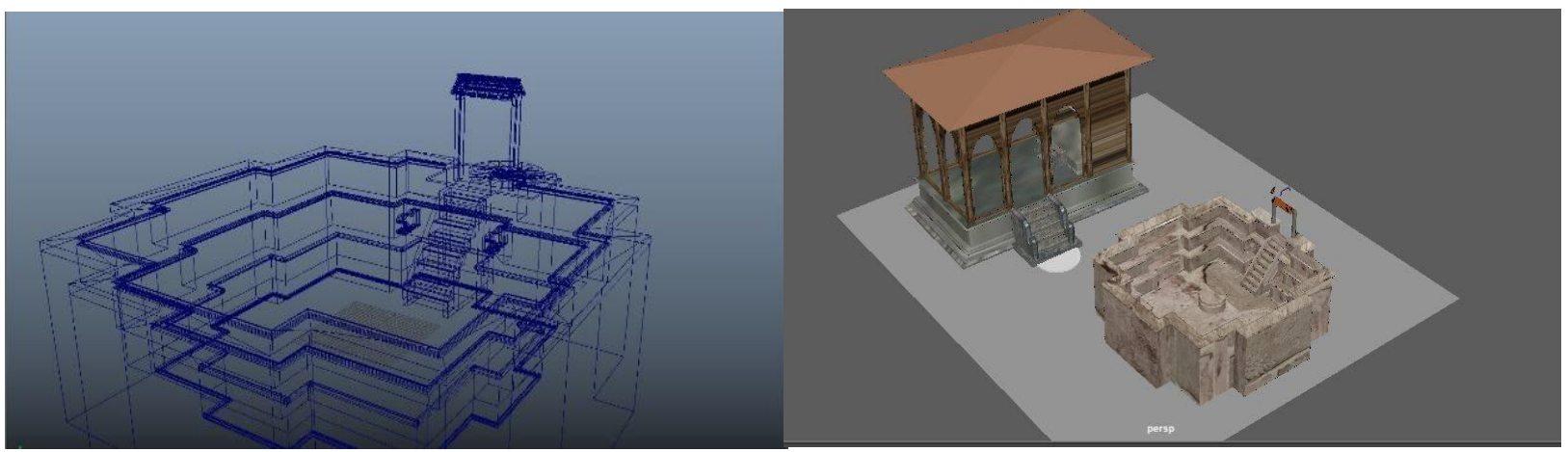

Fig. 7. Model of the Kumara Pond without texturing

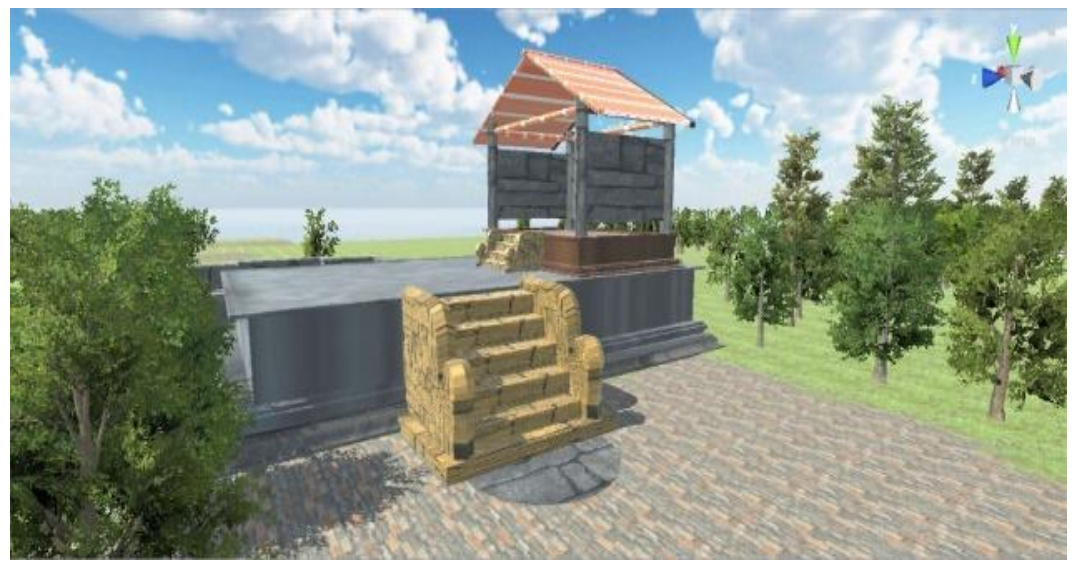

Fig. 8. Final Model of the Kumara Pond

The team created few user interfaces for the VR application as well. Fig. 9 is the main menu of the application. Main Menu Shows primary list of options available to the user. Fig 10 illustrate the Settings Menu of the Application. By using this menu user can change the graphic quality of the application. Such as Screen Resolution, Anti-Aliasing and Music Volume.

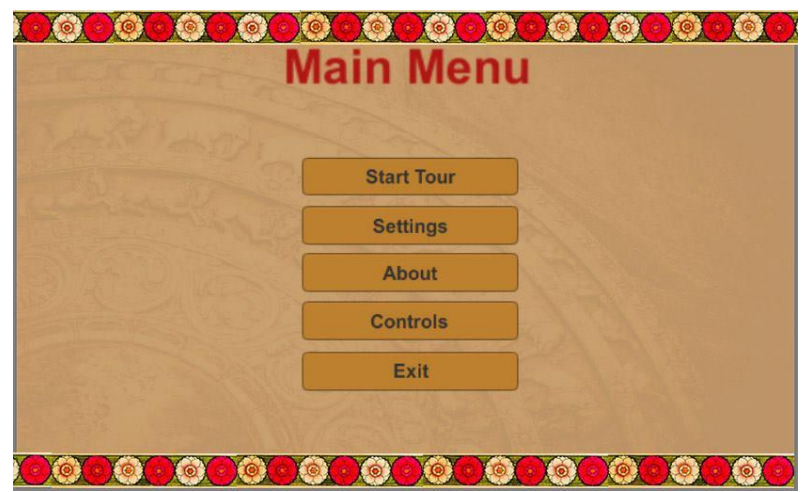

Fig. 9. Main Menu Interface

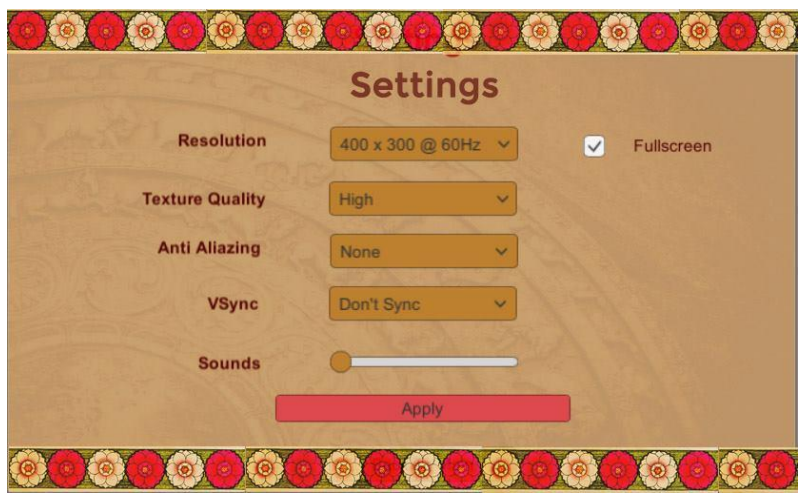

Fig. 10. Settings Interface

For pages other than the first page, start at the top of the page, and continue in double-column format. The two columns on the last page should be as close to equal length as possible. The Team started coding according to the requirements and the design discussed in previous phases. After the designing of the models and the interfaces, scripts were written for the narration and mini map.

The requirements are first developed as small units and then integrated to form a full system. These units are tested while they are being created to check the functioning of the different units of the application. After the coding of the system is completed it is forwarded to the testing team. 


\section{CONCLUSION}

"Purwalokanaya" is a virtual reality Application which has been created for entertainment and educational purposes. According to the research results, it was found that even though there are many books and ancient resources to learn about the "Polonnaruwa" History, very limited ways to gather knowledge through a dynamic and interactive environment. The Main goal of this research project is to give the user a virtual Reality experience inside Ancient City of "Polonnaruwa", which will provide a learning environment for students of all ages and the general public to know more about "Polonnaruwa" Kingdom. The major limitation was that when creating more realistic environment, highly detailed 3D models are required but all the 3D models have been modeled in low polygon counts due to limited memory space. Research team is considering to modify the Purawlokanaya Application in many ways as a future plan. Main plan is to upgrade the system to run in multiple platforms. It is planned to develop the application as an educational tool for school students to learn history. Adding up more effective animations is also included as a part of the future plan in order to increase the excitement throughout the Virtual tour.

\section{ACKNOWLEDGMENTS}

We would like to thank SLIIT computing academic and nonacademic staff for the kind support and guidance.

\section{REFERENCES}

[1] E. Gobbetti and R. Scateni, "Virtual reality: past, present, and future", P-arch.it, 2018. [Online]. Available: http://www.p-arch.it/handle/11050/682. [Accessed: 04Jan- 2018].

[2] Cheng, Y. S., Chen, Z. F., \& Chen , C. H. (n.d.). Virtualimage generation in 360-degree viewable image-plane disk-type multiplex holography. Chungli, Taiwan : Department of Optics and Photonics, National Central University. Retrieved March 2017
[3] Cho, Y. H., \& Daniel . (n.d.). A Conceptual Framework for Evaluating Effects of a Virtual Tour. Illinois, Urbana Champaign: Fesenmaier National Laboratory for Tourism and eCommerce University. Retrieved March 2017,fromdrfez@uiuc.edu

[4] Craighead, J., Burke, J., \& Murphy, R. (2007, January). Using the Unity Game Engine to Develop SARGE. Retrieved April 1, 2017

[5] Dylla, K., Frischer, B., Mueller, P., Ulmer, A., \& Haegler, S. (n.d.). Rome Reborn 2.0. Retrieved from https://bibliographie.unituebingen.de/xmlui/bitstream/ha ndle/10900/61447/09_Dylla_et_al_CAA2009.pdf?seque nce $=2 \&$ is Allo wed $=y$

[6] "Rome Reborn", Romereborn.frischerconsulting.com, 2017.[Online].Available:http://romereborn.frischerconsul ting.com. [Accessed: 05- Dec- 2017].

[7] "Digital Karnak: Welcome", Dlib.etc.ucla.edu, 2017. [Online].Available:http://dlib.etc.ucla.edu/projects/Karna k/. [Accessed: 05- Dec- 2017].

[8] "Acropolis Virtual Tour", Acropolis-virtualtour.gr, 2017. [Online]. Available: http://acropolis-virtualtour.gr. [Accessed: 05- Dec- 2017].

[9] "PublicVR - Project: Pompeii", Publicvr.org, 2017. [Online].Available:http://publicvr.org/html/pro_pompeii. html. [Accessed: 05- Dec- 2017].

[10] Team, "Angkor Wat, Cambodia", AirPano, 2017. [Online].Available:https://www.airpano.com/360DegreeVirtualTour.php?3D=Angkor-Wat-Cambodia. [Accessed: 05- Dec- 2017].

[11] "City of Polonnaruwa, Sri Lanka", http://lanka.com, 2018.[Online].Available:https://lanka.com/about/destinat ions/polonnaruwa/. [Accessed: 04- Jan- 2018]. 